\title{
Environmental governance and innovation: an overview
}

\author{
Chun-Ping Chang ${ }^{1} \cdot$ Jun Wen ${ }^{2} \cdot$ Mingbo Zheng ${ }^{3}$
}

Published online: 4 January 2022

(c) The Author(s), under exclusive licence to Springer-Verlag GmbH Germany, part of Springer Nature 2022

This special issue is on environmental governance and innovation. The theme is related to recent progress in environmental governance and its influence on innovation. This special issue is planned to introduce the latest leading research in the field of environmental governance. It is expected that the release of collected papers in this special issue will encourage future research on innovation consequences of environmental governance. This special issue received 19 papers, including one paper that was submitted twice. Among these 19 papers, 7 papers are rejected, and 12 papers are accepted. All accepted papers were reviewed by two anonymous referees on the subject.

These 12 papers cover a wide range of topics in environmental governance and innovation. These topics could be divided into four streams, including environmental policy and innovation, environmental governance at the microlevel, macroeconomics outcomes of environmental policy, and water quality management.

The first group of papers devotes their attention to the effect of environmental policy on innovation. Zhang and $\mathrm{Li}$ examined the impacts of environmental decentralization and environmental protection investment on green technology innovation. They showed that environmental decentralization promotes green technology innovation, while environmental pollution treatment investment inhibits green technology innovation when the environmental decentralization level is high. Shang, Tan, Feng, and Zhou investigate the relationship between environmental regulation, import trade, and green technology innovation. The authors found that import trade can promote green innovation development

Responsible Editor: Philippe Garrigues

Chun-Ping Chang

cpchang@g2.usc.edu.tw

1 Shih Chien University, Kaohsiung, Taiwan

2 School of Economics and Finance, Xi' an Jiaotong University, Xi' an, China

3 School of Economics and Management, Chang'an University, Xi' an, China under restrictive environmental regulations. Liu, Hou, Gao, and Tan analyze the linear as well as the nonlinear relationship between innovation and green total factor productivity. They state that innovation exerts a positive effect on green total factor productivity in general, while this effect is larger with a greater level of human capital, knowledge stock, and financial development. Mbanyele and Wang explore the impact of environmental regulation on innovation. They found that environmental regulation substantially promotes innovation and productivity.

The second group of studies focus on environmental governance at the micro-level. Han, Li, Xiang, Luo, and Chen examined the role of the institutional environment in green investment. They found that legal and cultural institutions play a role in promoting enterprise' green investment, while institutions in the political, economic, and financial dimensions do not. Chen, $\mathrm{Li}$, and Huang checked the influencing factors of corporate environmental information disclosure. The authors show that the relationship between influencing factors and environmental information disclosure will be mediated by corporate environmental management. Guo and Huang compared social welfare when choosing carbon tax or subsidy instrument. They found that the preferred instrument should be a carbon tax, not a subsidy, once the marginal environmental damage of the high carbon product increases.

The third group of studies focuses on macroeconomic outcomes of environmental policy. Guo, You, and Lee investigate the distributional effects of income inequality and country risk on $\mathrm{CO} 2$ emissions across developmental stages. They show that the marginal impact of inequality on emissions drops constantly with decreasing country risk at 10th to 50th quantiles at the global level. Zhao and Yang examine the applicability of a dynamic mode decomposition forecast algorithm. They found that this method validates the accuracy and application value. Song, Jing, Yan, and Sun examine the impact of government information transparency on sulfur dioxide emissions. They show that a city's government information transparency is negatively associated with its sulfur dioxide emission. 
The fourth group of papers takes issue with water quality management. Chen, Wang, Sun, Chen, Zhang, and Ye employ trophic level index (TLI), water quality index (WQI), modified Nemerow pollution index (NPI), and the random forest (RF) model to evaluate water quality. They found that dam construction, land use types, unstable hydrodynamic conditions, and trumpet-shaped estuary mainly aggravated the water quality degradation of Taihu Lake. Khullar and Singh assess water quality by using deep learning bi-, long-, and short-term memory (Bi-LSTM) network model. They show that the proposed deep learning Bi-LSTM model has better forecasting accuracy.

Publisher's note Springer Nature remains neutral with regard to jurisdictional claims in published maps and institutional affiliations.

Chun-Ping Chang Professor at the Shih Chien University at Kaohsiung, Taiwan; he also serves as an editor of Emerging Markets Finance and Trade. His research areas include political economy, environmental economics, energy economics, and panel data analysis. Dr. Chang had published his articles (over 130) in Research Policy, Energy Economics, Energy Policy, European Journal of Political Economy, European Journal of Finance, Economic Letters, Technovation, Technological Forecasting \& Social Change, etc.

Jun Wen professor, Vice Dean of School of Economics and Finance at the Xi' an Jiaotong University, Xian, China. His research areas include corporate governance, political economy, technological innovation, and energy economics. Professor Wen had published his papers in Research Policy, Energy Economics, Economic Modelling, Structural Change and Economic Dynamics, European Journal of Finance, etc.

Mingbo Zheng Assistant Professor of School of Economics and Management, Chang'an University, Xian, China. His research fields include innovation, environmental economics, and political economics. His work has been published in Economic Modelling, Structural Change and Economic Dynamics, Economic Systems, Emerging Markets Finance and Trade, etc. 